\title{
Integralidade na atenção e no cuidado a saúde
}

Integral Healthcare

Ana Maria Costa

Médica, Doutora em Ciências da Saúde pela Universidade de Brasília; Ministério da Saúde.

E-mail: ana.costaœsaude.gov.br

\section{Resumo}

Este ensaio apresenta uma discussão sobre a Integralidade em saúde. Apoiado na constatação de que a perda do equilíbrio da saúde nos processos de adoecimento não constituiu apenas fator médico-biológico, mas também um processo vinculado à história de vida do indivíduo, da família e da sociedade, elege como ponto de partida para a reflexão os poderes e limites de atuação dos profissionais de saúde, em especial o médico. Discute a fragmentação da ciência médica e a especialização de sua prática resultante da separação dos objetos em compartimentos estanques, obrigando o esforço interdisciplinar para a apreensão da totalidade da saúde. Analisa as relações de desigualdade entre médico e paciente, defendendo o diálogo como alternativa de redução desta desigualdade. A integralidade surge como discurso contra hegemônico na formação e nas práticas médicas, adotada pelo movimento sanitário brasileiro como um conjunto de atitudes desejáveis, em especial a valorização da associação entre as práticas de saúde e as práticas sociais. Finalmente destaca caminhos para a conquista de mais integralidade, partindo da delimitação das demandas e necessidades, em interação com os recursos tecnológicos de saúde disponíveis. Nesse contexto, discute, ainda, o acesso, alertando sobre a necessidade de enfrentamento do campo da micropolítica de saúde e suas articulações, fluxos e circuitos, baseada na lógica das necessidades dos usuários do sistema e na incorporação de valores éticos e técnicos.

Palavras-chave: Cuidado integral à saúde; Humanização na relação médico-paciente; Integralidade. 


\section{Abstract}

This paper discusses Integral Healthcare. Based on the realization that health imbalances stemming from diseases are due not only to medical-biological reasons, but also to processes related to the individual's life history, family, and society, this paper begins by discussing the capabilities and limitations of healthcare professionals, especially physicians. It then discusses the fragmentation of medical science and the specialization of medical practice into rigidly compartmentalized subject areas, and defends the need for interdisciplinary efforts in an integral approach to healthcare. It goes on to analyze the inequalities in doctor-patient relationships, championing dialogue as an alternative route for reducing these inequalities. Integral healthcare emerged as a way of curbing hegemony in medical training and practice, and has been adopted by the Brazilian health movement as a set of desirable attitudes, especially that of valuing the association between healthcare and social practices. In conclusion, the paper outlines ways forward to bring about more integral healthcare, starting with a discussion on user demands and needs with regard to available healthcare technological resources. It also discusses access issues within micro-level healthcare policies, systems, and flows, which need to be based on an understanding of the logic behind user needs, while also incorporating ethical and technical values.

Key words: Integral Healthcare; Humanized doctorpatient relationship; Integrality.
A perda do equilíbrio da saúde nos processos de adoecimento não constitui apenas fator médico-biológico, mas também um processo vinculado à história de vida do indivíduo, da família e da sociedade. Em todas as culturas, há manifestações do recolhimento interior provocado pelo sofrimento e pelo padecimento da dor. 0 doente deixa de ser quem era antes.

A doença é o lado sombrio da vida, uma espécie de cidadania mais onerosa, já que todas as pessoas vivas têm dupla cidadania: uma no reino da saúde e outra no reino da doença (Sontag, 1984, p.7). Portanto, o reconhecimento da cidadania do doente atribui direitos aos indivíduos nesta condição, incluindo o respeito às subjetividades presentes na sua relação com os profissionais de saúde.

No ensaio Além do Princípio do Prazer, Freud (1952) explica que, os processos anímicos são regulados por uma tensão entre o prazer e o desprazer. 0 domínio do princípio do prazer sobre os processos psíquicos faria com que a maior parte desses processos resultasse em prazer, o que contradiz a experiência humana real. De fato, existe uma forte tendência ao princípio do prazer, porém, a esta tendência, opõem-se outras forças, de forma que o resultados nem sempre correspondem ao domínio do prazer (Freud, 1952, p.221).

A Psicanálise usou a relação dialética entre Eros e Thanatos para tratar das forças permanentes, repressivas e não-repressivas, relacionadas à sexualidade, para a sustentação da vida ou para a conquista da morte, esta última, entendida como fuga inconsciente à dor e às carências vitais (Marcuse, 1999, p.47). 0 princípio da necessidade impõe-se como estratégia humana de controle da ordem permanente de Eros na sua busca desenfreada do princípio do prazer (Marcuse, 1999, p.193).

Ao afirmar que todos os instintos desejam reconstruir algo anterior relacionado à regressão ou reconstrução do passado, Freud traz a idéia de que os instintos vitais são, permanentemente, atraídos pelo seu estado antigo, anterior, seu estado inorgânico. Se essa atração instintiva está direcionada ao estado de partida, argumenta "que todos os seres viventes morrem por fundamentos internos de retorno ao estado inorgânico, logo, podemos dizer que a meta de toda a vida é a morte, ou que o inanimado era, antes, o animado" (Freud, 1952, p.251, tradução nossa). 
Desta forma se institui a ambivalência para o tema da saúde. De um lado, estão as sensações prazerosas por intermédio das quais se experimenta a leveza da sensação de vida. Do outro lado, igualmente sedutoras, estão as pressões e opressões, essa espécie de tração, que arrasta o indivíduo para baixo até chegar à condição da doença ou da morte.

Vista como um estado de equilíbrio, a saúde está sustentada por forças antagônicas compensadas. Nesse modelo, a perturbação do equilíbrio ou desequilíbrio somente pode ser evitada com um contrapeso. Porém, toda a intenção de compensar uma perturbação mediante um contrapeso significa, por sua vez, uma ameaça de novos desequilíbrios, em sentido contrário (Gadamer, 1996, p.129).

A aproximação possível para a saúde nesse contexto é a de que esta seja tal como o ritmo da vida: um processo contínuo no qual o equilíbrio estabiliza-se uma e outra vez (Gadamer, 1996, p.13o). Essa imagem dialética para a saúde, da manutenção do equilíbrio pelo desequilíbrio, configura um modelo muito ilustrativo porque permite demonstrar a periculosidade subjacente a toda intervenção sobre ela.

Tal qual ocorre em todas as perdas humanas, a esperança de retornar ao estado saudável não abandona o doente e compõe o conjunto de forças atuantes nessa dinâmica do processo saúde-enfermidade. Representa a força de Eros, na imagem da Psicanálise, atuando no sentido contrário de Thanatos. Se a recuperação do equilíbrio natural é atingida com êxito, o processo de restabelecimento devolve também ao convalescente o equilíbrio vital, no qual, previamente, estava. No fundo, não se trata apenas de um único grande equilíbrio, mas de um estado em torno do qual este equilíbrio oscila (Gadamer, 1996, p.57).

Da mesma forma o cuidado com a saúde e o tratamento médico são regidos pela experiência do equilíbrio. Essa experiência, mediada pela periculosidade, deveria, por exemplo, conduzir à maior racionalização do consumo de medicamentos ou a um maior rigor na indicação de exames e procedimentos. Colocase, então, a pergunta: quais são os poderes e os limites da intervenção humana diante dessas situações?

Esta pergunta não se aplica apenas aos cientistas, mas também nas situações em que o cuidado à saúde é realizado por meio de ritos religiosos. Os curandeiros e os bruxos, por exemplo, pela experiência acumu- lada no desenvolvimento de práticas aplicadas desde os tempos remotos, desenvolveram suas habilidades, cuja validade está mantida, ainda que sejam desconhecidos os motivos de sua eficácia. Mesmo admitindo que esse conhecimento seja subjetivo e que, em grande medida, seja incontrolável e instável, não há dúvidas de que essas práticas constituem saberes que a ciência já não pode mais ignorar (Gadamer, 1996, p.13).

0 ponto de partida para a reflexão sobre os poderes e limites de atuação do médico é admitir que a arte de curar é o objeto da ação do médico ou, ampliando, também é objeto dos serviços de saúde.

Um diálogo de Sócrates e Fedro (Platão, 2003, § 270, p.112) fornece importantes elementos para a discussão contemporânea do tema da totalidade. Os filósofos estabelecem um paralelo entre a arte de curar e a arte da retórica. Sócrates adverte sobre a necessidade de retomar a noção do todo na arte da retórica e argumenta que "passa mais ou menos a mesma coisa que na arte de curar”. À pergunta de Fedro sobre o significado desse argumento, Sócrates responde: “[...] as duas artes são bem distintas pelo seu objeto, posto que uma se relaciona com o corpo e outra com a alma".

Em ambos os casos, diz Sócrates: “(...) tens que levar em conta, se quiseres, não só pela prática e por regras empíricas, mas de acordo com a arte, uma dar força e saúde, ministrando remédios e alimentos e a outra infundir a convicção que desejas, tornando o homem virtuoso mediante discursos e argumentos legítimos”. E então pergunta Sócrates para seu jovem amigo: "E crês que se pode entender a natureza da alma sem conhecer a natureza do todo?". Ao que Fedro responde: "Se dermos crédito a Hipócrates, que é um Asclepíades, nem sequer o corpo se pode conhecer sem tal método" (Platão, 2003, § 270, p.112).

A noção do todo relacionada à saúde é, portanto, preocupação antiga e afirma que o tratamento do corpo pela ação médica não é possível sem o simultâneo tratamento da alma. Mais ainda, que, porventura, nem isso seja o bastante, pois talvez até seja impossível fazê-lo sem o conhecimento do ser na sua integridade.

A palavra integridade em grego, hole ousia, aponta para o sentido ser saudável. O ser completo e saudável constitui a referência para a saúde. Nesse sentido, a doença e a consciência sobre ela advêm da perturbação do estado de sanidade, manifesto na corporeidade humana (Gadamer, 1996, p. 90). 
A integridade do corpo não pode, entretanto, dissociar-se das outras integridades que conformam o estado de sanidade. A medicina grega é rica em exemplos de interferências das estações do ano, da temperatura, da água e da alimentação na saúde - exemplos de como os fatores climáticos e ambientais interferem diretamente naquilo cujo equilíbrio se pretende reparar ou restabelecer. Neste sentido, o médico deve observar além do caso a tratar, captando o homem na totalidade de sua situação de vida (Gadamer, 1996, p.57).

0 reconhecimento de que as condições nas quais se encontra o corpo afetam a totalidade do indivíduo exige do médico a incorporação de uma dimensão que ultrapasse o objeto imediato de seu saber e de sua habilidade, tornando a sua situação no mundo intermediária entre um profissionalismo desligado do humano e uma aposta pessoal no humano (Gadamer, 1996, p.56). Essas condições não se restringem aos aspectos ambientais, mas estendem-se às relações culturais, sociais e também às subjetividades.

A confiança no médico é fruto de um processo de conquista por meio de seu poder de convicção. Sem a confiança, não existe a colaboração do doente, que é essencial para a cura. Esse fator curativo pertence a uma dimensão completamente distinta da ação físico-química dos medicamentos sobre o organismo ou mesmo da intervenção cirúrgica e requer que o médico saiba delimitar seu poder como profissional e adote mais critérios na sua atuação (Gadamer, 1996, p.34).

Nesses critérios, deverão estar incluídas preocupações e condutas que evitem a iatrogenia e efeitos danosos aos doentes, decorrentes da prática médica. A dependência ao médico causa efeitos tão perversos aos doentes quanto as iatrogenias medicamentosas ou por procedimentos médicos. A autonomia do sujeito que recorre à prática médica representa a perfeição da arte da medicina e ocorre quando o médico deixa o outro em liberdade.

Dada a complexidade do objeto da saúde, é mister reconhecer que a ciência médica, por si só e tal como se apresenta, não tem competência para a arte de curar, porque são muitos os fatores que intervêm nesse processo. Portanto, na habilidade do médico, conta também aquela proveniente de suas experiências de vida mais secretas, de sua cultura e subjetividade.

Ainda que os avanços da medicina tenham contribuído e continuem contribuindo para a ampliação do poder de ajuda deste profissional no alívio da dor e do sofrimento humano, há que se reconhecer que não somente este progresso científico da medicina clínica ou a introdução de métodos químicos da biologia interferem nas práticas médicas. A arte de curar envolve não somente o combate à doença, mas também inclui a convalescença e, finalmente, o cuidado da saúde (Gadamer, 1996, p.124).

Na história da medicina, é notável uma certa tensão entre as expressões ciência e arte. A arte de curar está voltada para uma missão de restabelecimento de algo natural, distinta da arte de produzir coisa ou objeto artificial. Dentro desse conceito de arte, que se encontra nos limites do que é a ciência, é evidente que a arte da medicina sobre o corpo humano seja um conceito problemático.

A essência da arte de curar consiste em poder voltar a produzir o que já estava produzido, em recuperar o equilíbrio do estado saudável. Por isso, o saber e o fazer médicos representam a capacidade de modificar determinada situação, por meio da arte. Poder-seia afirmar que o médico produz saúde por meio de sua arte, no entanto, essa afirmação seria inexata, uma vez que o que o médico produz não é uma obra, um ergon, algo que demonstra a sua capacidade de produzir (Gadamer, 1996, p.46).

O fato é que a arte exercida pela medicina não é muito peculiar, já que nem todos os seus aspectos coincidem com o que os gregos chamam techne e com o que nós, às vezes, chamamos arte e outras vezes, ciência.

O conceito de techne é uma criação da mentalidade grega, ou seja,do livre pensamento sobre as coisas e é identificado como aquele saber que representa uma determinada habilidade segura, desde o seu começo, em relação a uma determinada produção. Portanto, o conceito grego techne não se refere à aplicação prática de um saber teórico, mas constitui uma forma própria de conhecimento técnico. (Gadamer, 1996, p. 45). o logos, reconhecido como a disposição para dar conta dos fundamentos de tudo o que o homem considera como verdadeiro, ao ser introduzido nas origens da medicina, faz com que ela passe a constituir o melhor exemplo de transformação do que era acumulação de habilidades e de saberes dos curandeiros, em ciência, a partir de então, protagonizada pelos médicos.

Em decorrência da aplicação dos métodos da ciência moderna ao campo da medicina, a civilização oci- 
dental adota o conceito grego. 0 médico abandona a figura do curandeiro rodeado de mistérios sobre seus poderes mágicos e passa a ser um homem de ciência. 0 médico passa a conhecer a razão pela qual uma determinada forma de cura tem êxito; entende a ação da cura e passa a perseguir a relação entre causa e efeito (Gadamer, 1996, p.49).

Entretanto, se a produção do médico é o restabelecimento da saúde do enfermo, mas estar saudável não significa apenas estar curado, torna-se difícil determinar se o resultado dessa produção é conseqüência do êxito do conhecimento e da capacidade do médico. Esse dilema abre uma interrogação: "em que medida o êxito da cura se deve ao tratamento acertado do médico e, em que medida, colaborou com ele a própria natureza?" (Gadamer, 1996, p. 47).

Segundo Canguilhem (2002, p.188), para quem a medicina não é ciência, mas práxis nutrida pelos conhecimentos das outras ciências:

Ocorre com a medicina o mesmo que com as outras técnicas, pois a medicina é uma atividade que tem raízes no esforço espontâneo do ser vivo para dominar o meio e organizá-lo segundo seus valores de ser vivo. É nesse esforço espontâneo que a medicina encontra seu sentido mesmo não tendo encontrado, antes, toda a lucidez crítica que a tornaria infalível. Eis por que, sem ser ela própria uma ciência, a medicina utiliza os resultados de todas as ciências a serviço das normas da vida.

Assim sendo, a medicina estimula a expansão do conhecimento sobre a vida, pois está voltada para o alívio do sofrimento humano, atuando por meio do conjunto de práticas que os humanos realizam para socorrer outros humanos, para que vida possa ser usufruída de forma mais rica em todas as suas dimensões.

Nesse contexto da ciência moderna, em que o espírito prevalecente desde o século XVII favorece a concepção mecanicista para o fenômeno da vida, Gadamer (1996) afirma que a forma mais aproximada de definir a ciência da medicina seria considerá-la como a ciência da doença, da enfermidade. Seu argumento baseia-se na constatação de que a enfermidade é o que aflora como perturbador do equilíbrio, o perigoso, aquilo que se quer combater.

A ciência moderna do século XIX impôs à medicina o pensamento metódico da matemática experimental, obedecendo ao impulso da segurança conferida pelo método ligado ao cientificismo e à objetividade.
Toda a produção de conhecimentos médicos está orientada, em primeiro lugar, para o domínio dos fenômenos da doença e da enfermidade, "é como se estivesse forçando a natureza ali onde se manifesta a doença. O importante para a ciência médica é dominá-la" (Gadamer, 1996, p.121).

Nesse mesmo sentido, Canguilhem (2002, p.165) assevera que a fisiologia e a patologia, e não a medicina, são as herdeiras do manto da ciência, sobre as quais recai todo o arsenal do método científico, embora alerte sobre a impropriedade destas disciplinas em teimar sobre os conceitos de normal e patológico.

O conceito de totalidade para a medicina, em razão de seu contraconceito, o de especialização, tornouse necessário e significativo. A especialização é uma tendência irrefreável da ciência moderna e de todos seus procedimentos.

A ciência médica contemporânea está perdida no labirinto das especialidades, evidenciando até um certo estranhamento sobre a orientação para a totalidade. A especialização não se limita a ser uma tendência para o campo da medicina; ela está em todas as disciplinas da investigação científica, e é resultado da separação dos objetos em compartimentos estanques obrigando ao esforço interdisciplinar para a apreensão da totalidade dos temas (Gadamer, 1996, p.122).

\section{Diagnosticar, Tratar e Cuidar}

A medicina sustenta sua legitimidade social na capacidade de responder ao sofrimento humano em decorrênciadas doenças. Por isso, desenvolveu um conjunto de conhecimentos e técnicas voltados ao reconhecimento de sinais e sintomas associados à doença, que resultam em sofrimento e, da mesma forma, um conjunto de conhecimentos sobre as formas de enfrentamento de tais doenças.

A palavra grega symptom era usada para designar as manifestações mais evidentes de uma doença e, ainda hoje, o termo sintoma é usado com esse sentido. $\mathrm{Na}$ abordagem da doença, não é a saúde que se destaca, a despeito de os valores standard dos fenômenos biológicos serem estabelecidos sobre ela. Todavia, a saúde não permite a imposição de valores standards estabelecidos sobre as bases de certas médias obtidas em diferentes experiências. Tal imposição seria, no mínimo, imprópria para o caso individual. 
As medições e seus padrões de métodos de medição valem-se de uma convenção sobre a base da qual as coisas são aproximadas pelos homens e submetidas a exames orientados pelo método científico e, desta forma, têm seu uso consagrado na prática médica. Porém, as coisas possuem uma medida natural inerente. Se não se pode medir a saúde é porque, em realidade, trata-se de um estado de medida interna, não mensurável.

Por isso, a avaliação do estado de saúde ganharia sentido quando o paciente se declarasse doente (Canguilhem, 2002, p. 145; Gadamer, 1996, p. 123), no momento em que suas sensações subjetivas fossem respeitadas no processo de elaboração do diagnóstico, por meio da recuperação da pergunta: como você se sente?, em vez de o que você sente?

O que está sendo reafirmado aqui evoca a constatação de Canguilhem (2002, p. 145) acerca da imprecisão entre o normal e o patológico:

Se o normal não tem a rigidez de um determinativo para todos os indivíduos da mesma espécie e o incita a flexibilidade de uma norma que se transforma em sua relação com condições individuais, é claro que o limite entre o normal e o patológico torna-se impreciso. No entanto, isso não nos leva à continuidade de um normal e de um patológico, idênticos em essência,pois há uma relatividade quanto às variações quantitativas, e essa relatividade da saúde e da doença é bastante confusa para que se ignore onde termina saúde e onde começa doença.

Do ponto de vista formal, o diagnóstico é a subordinação de um dado caso a uma norma geral de uma síndrome ou enfermidade. Pode-se cogitar que a verdadeira arte da medicina resida na definição do diagnóstico, momento no qual é preciso colocar em prática a habilidade individual do médico, uma vez que se exige a convergência de seus múltiplos conhecimentos para a compreensão sobre o que está acontecendo, a fim de que possa definir as suas intervenções.

Não resta dúvida de que para exercer essa função são requeridos conhecimentos médicos gerais e específicos, porém esses não bastam. 0 diagnóstico equivocado e a correlação errônea geralmente não são atribuídos à ciência, mas à “arte”, que é, nessa última instância, a capacidade de avaliação e ajuizamento do médico (Gadamer, 1996, p.33).

A valorização das características e situações indi- viduais deveria ser o norte da ação médica, por meio do reconhecimento da falta de limites claros entre as condições normais e as patológicas. Canguilhem afirma que:

A fronteira entre o tempo normal e o patológico é imprecisa para diversos indivíduos considerados simultaneamente, mas é perfeitamente precisa para o único e mesmo indivíduo considerado sucessivamente. Aquilo que é normal, apesar de ser normativo de determinadas condições, pode se tornar patológico em minutos se a situação permanecer inalterada. 0 indivíduo é que avalia essa transformação porque é ele quem sofre suas conseqüências, no próprio momento em que se sente incapaz de realizar as tarefas que a nova situação lhe impõe (Canguilhem, 2002, p.145).

0 passo seguinte ao diagnóstico consiste no tratamento, no estabelecimento de um programa de intervenções. Mas em que consiste o tratar? O sentido de cuidado confere dimensão ética ao processo de tratamento.

A Fábula do Cuidado, cuja autoria é atribuída a Gaius Julius Hyginus conta que Cuidado, ao atravessar um rio, deu forma a uma porção de barro que ali encontrou (Heidegger, 1989, p. 263). Enquanto apreciava o objeto construído, surgiu Júpiter, a quem Cuidado solicitou que soprasse espírito naquele objeto por ele esculpido, o que Júpiter fez de bom grado. Cuidado, então, quis dar um nome àquele objeto, mas Júpiter o proibiu, exigindo que o objeto assumisse o seu próprio nome, gerando assim uma discussão entre os dois deuses.

Nesse momento, a Terra passa, também, a reivindicar que a criatura tenha o seu nome, argumentando que a mesma fora feita de sua matéria, o barro. A discussão foi tamanha que chamaram Saturno para atuar como árbitro no conflito instalado entre eles. Saturno, então, toma a seguinte decisão:

Você, Júpiter, deu-lhe o espírito; receberá de volta este espírito por ocasião da morte desta criatura. Você, Terra, deu-lhe o corpo e, portanto, receberá também de volta este corpo quando esta criatura morrer. Mas você, Cuidado, como foi quem primeiro moldou o barro, esta criatura ficará sob seus cuidados enquanto ela viver. E, quanto a esta discussão entre vocês acerca do nome, decido eu: esta criatura será chamada Homem, isto é, feita de húmus, que significa terra fértil (Heidegger, 1989, p.263). 
Tratar significa cuidar, tratar corretamente e isso consiste no reconhecimento do outro desdobrado no modo como o médico ocupa o seu lugar na relação com o doente. Envolve, pois, que, ao falar com o outro, o faça de bom modo, livre de coerção, impedindo-o de tornar-se algo diferente do que é. Implica, também, não obrigá-lo a aceitar medidas, condutas ou prescrições decididas por quem dele trata. Esse cuidado somente se tornará possível se houver o reconhecimento do outro como alguém diferente de si mesmo e apenas esta constatação poderá orientar o melhor caminho nesta relação assimétrica, em todos os seus sentidos, entre médico e paciente.

Tratar alguém com cuidado implica atuar cautelosamente sempre que isso se fizer necessário. Neste sentido, todo paciente representa alguém com quem se deve proceder com cautela devido à sua fragilidade e situação de vulnerabilidade. Esse ser indefeso necessita, portanto, ser cuidado. Diante da distância presente na relação entre médicos e pacientes, esses atores devem buscar encontrar um terreno comum no qual possam se entender, e esse terreno comum constitui o diálogo, o único instrumento capaz de diminuir esse relacionamento assimétrico e distante (Gadamer, 1996, p.142).

O diálogo constitui parte do tratamento cuidadoso e domina uma dimensão decisiva de toda a ação médica. Ele humaniza a relação entre indivíduos que são fundamentalmente distintos, permitindo a aproximação e a confiança necessária ao processo da cura. O estabelecimento de relações desiguais, como é o caso da relação entre médico e paciente, configura um dos aspectos mais difíceis no trato entre os homens (Gadamer, 1996, p.128). A atitude autoritária do médico que se nega ao diálogo e se defende dos argumentos do leigo está conduzindo ao extremo um padrão de ciência objetiva na fundamentação de suas atitudes, posturas e ações que, em última instância, resulta na negação do outro.

Nesse sentido, o médico não pode abusar do poder e pretender dominar o paciente, mesmo que esta possibilidade se mostre muito sedutora. Deve restringirse a aconselhá-lo e ajudá-lo, se é que isso é possível. Porém, deve ter consciência, também, de que o paciente estará sob seu tratamento e cuidado somente até que se recupere. Desta forma, o médico deve inspirar confiança na sua capacidade de cuidar do outro, po- rém não deve impô-la, ou seja, não deve pôr em jogo sua autoridade pelo fato de, a todo custo, desejar obter a confiança do doente (Gadamer, 1996, p.125).

Por isso, estar sob tratamento de um profissional médico não implica estar sob suas ordens ou determinações. 0 tratamento requer que se conceda a liberdade de decisão ao doente e não somente que se formulem prescrições, definam-se procedimentos e exames. Essa postura significa assumir uma certa responsabilidade no exercício de atenção e cuidado, desde que esta não comprometa a liberdade do doente.

\section{A Integralidade da Saúde}

Em suas origens, o debate sobre a integralidade em saúde remonta aos anos 196o, época em que surgiram grandes questionamentos e críticas sobre as atitudes fragmentadas no ensino médico adotadas pelas escolas médicas nos Estados Unidos. Isso ocorreu em função da demanda da chamada "medicina integral" (Mattos, 2001, p.44).

O fundamento dessa crítica recaiu sobre o privilégio conferido às especialidades na formação médica, cuja tendência era a de recortar o corpo humano de acordo com o seu funcionamento, ou seja, em sistemas ou aparelhos, desviando o olhar da totalidade dos indivíduos. Essa situação impediaque os estudantes e, posteriormente, os médicos, tivessem a possibilidade de apreender as necessidades mais abrangentes de seus pacientes. A fragmentação, freqüentemente adotada pelos profissionais, era vista também como reducionista, já que o conhecimento médico nas diversas especialidades ressaltava as dimensões exclusivamente biológicas em detrimento das considerações psicológicas e sociais acerca do indivíduo e do processo de adoecimento (Mattos, 2001, p.45).

A crítica formulada pelos adeptos da medicina integral sobre a formação acadêmica que conduzia à fragmentação, levou à implementação de reformas curriculares e à introdução de novos currículos nas escolas médicas. Estes tinham como enfoque orientar mudanças de atitudes que promoveriam um ensino não-reducionista e menos fragmentado e, conseqüentemente, a formação de futuros médicos que fossem capazes de apreender de seus pacientes suas necessidades de modo mais integral (Mattos, 2001, p.45).

Desta forma, o discurso inaugural da integralidade 
abarca um conjunto de atitudes éticas e técnicas desejáveis para os médicos relacionadas à sua possibilidade de compreensão e apreensão ampliada das necessidades dos indivíduos.

Mattos (2001, p.46) lembra que, no Brasil, o movimento da medicina integral associou-se ao movimento da medicina geral comunitária ou da medicina preventiva, constituindo, posteriormente, uma das bases do movimento sanitário que se consolidou nos anos 1980. Por meio dessa articulação, mediada por ideologias similares e relacionadas às críticas sobre a prática da atenção e cuidado à saúde e também à saúde pública tradicional, tal como praticada nos EUA, foram incorporadas matizes bastante específicas que constituíram o campo da saúde coletiva.

Para o autor, o campo da saúde coletiva foi construindo o seu eixo de interpretação de forma bastante aproximada ao da medicina integral ao considerar as práticas em saúde como práticas sociais. Desta forma, as críticas estenderam-se às relações da prática de assistência médica privada, ao capital, ao lucro e convergiram na proposta de conquista da saúde como direito dos indivíduos, exigindo a presença do Estado no seu provimento e regulação do mercado.

No mesmo contexto, a crítica à medicalização (decorrente da condição de reféns na qual o complexo médico industrial coloca os profissionais médicos); à prática liberal da medicina e à exclusão de significativa parcela da população da atenção e cuidado médicohospitalar compõe o mosaico social sobre o qual a matriz de base marxista adotada conformou o campo coletivista e o próprio movimento sanitário brasileiro.

A atitude fragmentária e reducionista da prática médica foi associada à própria racionalidade médica e ao projeto da medicina, conformado na modernidade e orientado para a eficiência. Para resgatar uma postura integral, seria necessário superar alguns limites da racionalidade médica sobre a qual, se sabe agora, não se produz, mas reproduz-se na escola médica (Mattos, 2001, p.47).

A fragmentação e a racionalidade inspiraram o sistema de assistência médica no Brasil anterior ao SUS. O primeiro esteve pautado por sistemas paralelos de assistência médico-hospitalar previdenciária para ações e procedimentos de cura e recuperação, e pela rede pública voltada às ações de prevenção e promoção da saúde. É por isso que o primeiro sentido para a integralidade em saúde relaciona necessidade de articulação entre as práticas de prevenção e assistência, envolvendo necessariamente a integração entre serviços e instituições de saúde.

Embora a integração dos níveis e das instituições prestadoras de serviços de atenção e cuidado resulte em maior integralidade, ela é bem mais do que isso. O ideário da integralidade compõe um processo que se inicia na formulação de políticas do nível macro pelo Estado, passa pela gestão e gerência nos distintos níveis até a produção de ações de cuidado de saúde por meio das práticas para a atenção e o cuidado dos indivíduos.

Nesse contexto, a integralidade surge da ausência de algo, como expressão da insatisfação com as maneiras como estas práticas vêm sendo realizadas. Camargo (2001) destaca importantes interrogações ao reconhecer que a palavra integralidade não pode nem ao menos ser chamada de conceito, mas se trata de uma rubrica conveniente para o agrupamento de um conjunto de tendências cognitivas e políticas, com alguma relação entre si, mas não completamente articuladas" (Camargo, 2001, p. 12).

Buscando respostas às suas interrogações, Camargo (2003) identifica um conjunto de tradições argumentativas, que desembocam no "agregado semântico da integralidade":

"[...] por um lado, um discurso propagado por organismos internacionais, ligado às idéias de atenção primária e de promoção de saúde; por outro, a própria demarcação de princípios, identificada em pontos esparsos da documentação oficial das propostas de programas mais recentes do Ministério da Saúde em nosso país; por fim, as críticas de proposições sobre assistência saúde de alguns autores acadêmicos em nosso meio. Essa não definição talvez explique, ainda, mesmo que parcialmente, a clara escassez bibliográfica sobre o tema." (Camargo, 2003, p.37).

$\mathrm{O}$ atual conhecimento sobre as doenças, em alguns casos, permitiu à medicina antecipar-se à manifestação dos sintomas e às vezes, até mesmo à instalação da doença. Surgiram muitas técnicas capazes de reconhecer doenças antes que estas produzam sintomas por meio da identificação de fatores de riscos relacionados à probabilidade de doença (Mattos, 2001, p.49). Associada à integralidade, surge ainda a recomendação de que o médico não se atenha ao sofrimento ma- 
nifesto pelo paciente, mesmo que as pessoas busquem médicos por apresentarem algum desequilíbrio manifesto por um incômodo ou sofrimento (Costa e cols, 1998, p. 46).

No entanto, apesar dos incontestáveis resultados para a saúde das coletividades, decorrentes da aplicação das práticas de diagnóstico precoce e de prevenção, tais práticas tipificam um processo de medicalização, por não se constituírem demandas explícitas dos pacientes. Por meio dessas práticas, os profissionais de saúde podem invadir a vida privada das pessoas, ao proporem mudanças de hábitos e atitudes no modo de viver, regulando a saúde, os comportamentos e os corpos.

A medicalização é vista criticamente como o excesso de intervencionismo médico sobre os corpos e vida das pessoas e está relacionada ao abuso do poder médico e também à expansão do consumo de bens e serviços de saúde de interesse para o mercado. Quando ela se realiza por meio de ações preventivas e promocionais da saúde, não está isenta destas características atribuídas a qualquer processo de medicalização. Resta, então, o desafio de distinguir entre o intervencionismo e a violência, relacionados à medicalização, e à apreensão e compreensão das necessidades de ações e serviços de saúde que um paciente apresenta.

Esse desafio implica um passo a mais rumo à integralidade, cujo conhecimento das necessidades e demandas individuais e coletivas acerca da saúde devem ser resultantes da permanente interação dos atores na relação demanda e oferta, nos diversos níveis de atenção à saúde individual e coletiva. No plano individual, a integralidade é construída no ato da atenção individual e, no plano sistêmico, esta encontra suas garantias nas ações oferecidas pela rede de serviços, nos quais os aspectos subjetivos e objetivos sejam considerados (Pinheiro, 2001, p. 65).

Desta forma, delimitar as demandas deve ser valorizado no diagnóstico das necessidades de saúde. A demanda de serviços de saúde surge da percepção de dor e sofrimento por parte do doente em interação com os recursos tecnológicos de saúde disponíveis. Logo, demanda e oferta são dialeticamente co-produzidas pelas relações entre as dimensões do sofrimento (demanda) e da atenção (oferta) (Camargo, 2003, p.38).

0 conceito complexo da saúde cria um universo de necessidades que abrange mais do que o âmbito do setor de saúde. Mesmo que produtoras de saúde, as necessidades e demandas de outros setores de políticas sociais não devem seduzir o setor da saúde ao desvio de seu objeto. No entanto, os gestores das instituições de saúde também não podem desconhecer que a demanda em saúde é resultado de uma interação complexa entre fatores de ordem cultural remetidas aos serviços e aos profissionais de saúde, ultrapassando, muitas vezes, a procura por atenção médica condicionada pelos agravos à saúde.

Afirmando que não há possibilidade de integralidade e eqüidade sem a garantia da universalidade do acesso, Cecílio (2001, p.113) alerta que esses dois conceitos - integralidade e eqüidade - constituem os objetivos da atenção à saúde. Para o autor, além da discussão do simples consumo e acesso a determinados serviços, o debate sobre a integralidade remete ao campo da micropolítica de saúde e suas articulações, fluxos e circuitos. Isso implica, necessariamente, repensar aspectos importantes da organização do processo de trabalho, gestão e planejamento, construindo novos saberes e adotando inovações nas práticas em saúde. É necessário, portanto, reconhecer que as necessidades em saúde são determinadas social e historicamente, mesmo quando apreendidas e transformadas em práticas na sua dimensão individual.

Logo, o desafio é conseguir construir uma conceituação de necessidade de saúde com potencial de ser apropriada e implementada pelos trabalhadores de saúde no seu cotidiano, permitindo uma mediação entre a "incontornável complexidade do conceito de necessidade de saúde e sua compreensão e apropriação pelos trabalhadores, visando a uma atenção mais humanizada e qualificada” (Cecílio, 2001, p.114).

Portanto, a complexidade do objeto da saúde exige recriar a atuação dos profissionais de vários campos do conhecimento que atuam na saúde, já que a complexidade não é redutível à organização da atenção em determinado nível e envolve a ação dos distintos profissionais das diversas disciplinas complementares do campo da saúde.

Sendo assim, cabe defender a integralidade como valor a ser sustentado nas práticas dos profissionais de saúde, ou seja, um valor que se expressa na forma como os profissionais responderão aos pacientes que os procuram. 
A proposta é que a integralidade não deva ser transformada em um conceito, mas um ideal regulador, um devir. Algo como ideal de objetividade para investigação científica, impossível de ser plenamente atingido, mas do qual, constantemente, buscamos nos aproximar. Vê-se, portanto, que, num paradoxo, a integralidade é ao mesmo tempo inalcançável e indispensável (Camargo, 2003, p.40).

Ao propor a criação de novos significados para distintas dimensões das necessidades de saúde - desde os modos de vida, o acesso às tecnologias, a criação de vínculos afetivos entre usuários e serviços e a necessidade de autonomia - Cecílio (2001, p.114) sistematiza um conjunto de desafios para os serviços pautados, essencialmente na micropolítica do trabalho cotidiano em saúde. Nesse conjunto de desafios, destaca-se, especialmente, o que diz respeito à criação de vínculos afetivos e de autonomia. Trata-se de duas situações originadas da relação entre o usuário e a equipe ou o profissional, portanto, entre pessoas.

Quanto a relação de confiança entre estes atores, o autor defende que o reconhecimento do vínculo não deve estar restrito à simples adscrição do indivíduo a um serviço ou a inscrição formal a um programa, mas inclui o estabelecimento de uma "relação contínua no tempo, pessoal e intransferível, calorosa e mediada pelas subjetividades" (Cecílio, 2001, p. 115).

Em relação à autonomia, o destaque deve ser dado à necessidade de cada pessoa obter graus crescentes de autonomia na vida. O significado disso relacionase com a oferta de informação e educação em saúde, mas não se faz exclusivamente por este caminho. A autonomia implica a possibilidade de reconstrução dos sentidos da vida pelos sujeitos e esta ressignificação assume importância no seu modo de viver. Isso inclui a luta pela satisfação de suas necessidades, da forma mais ampla possível e relações mais simétricas entres usuários e trabalhadores de saúde.

O espaço de encontro do usuário com a equipe é o espaço da conversação destinado à aproximação entre profissionais e usuários (Gadamer, 1996, p.128), no qual deve prevalecer a capacidade de escuta de forma a permitir a apreensão das necessidades de saúde trazidas por aquela pessoa que busca o serviço. Os trabalhadores que atuam nos serviços devem ser capazes de não modelar as demandas trazidas pelos usuários de acordo com o ofertado pelo serviço, como regular- mente acontece. Da mesma forma, não deve prevalecer uma lógica dos profissionais na organização e sistemática de funcionamento dos serviços, mas aquela relacionada às necessidades dos seus usuários.

O delineamento da demanda deve se dar pela escuta das necessidades e os serviços devem se declarar impotentes para resolvê-las nas suas múltiplas dimensões. Os profissionais devem se aproximar de suas impotências humanas e lidar com seus limites e dificuldades. Demandas e necessidades não são, necessariamente, a mesma coisa. Necessidades podem estar relacionadas a desejos e aspirações subjetivas distantes dos sintomas que levaram o indivíduo à consulta.

As modalidades de atenção, por sua vez, também são produtos dos processos históricos acumuladores de múltiplas influências e articulações oriundas das distintas culturas que atuam sobre elas. Isso implica dizer que o retrato da atenção à saúde em um dado instante é resultado de processos constantes, que se ajustam uns aos outros, e a superação das insuficiências percebidas não se dará pela produção de pequenos ajustes em pontos isolados de sistema (Camargo, 2003, p.38).

Consoante com esse sentido, Cecílio (2001, p.116) apresenta o conceito de "integralidade focalizada", aquela identificada no espaço bem delimitado, focalizado, de um serviço de saúde, referida ao caso de uma experiência de um determinado município ou serviço de saúde, conquistada por meio do esforço e confluência dos vários saberes de uma equipe multiprofissional.

Resta registrar que a descentralização do sistema brasileiro de saúde vem possibilitando o desenvolvimento de inovações pautadas por ações de solidariedade, de cooperação e apoio mútuo, que tendem a se estabelecer, tornando-se o ponto de partida para renovação dos modelos e práticas de atenção e cuidado a saúde. Nesse contexto tem sido possível identificar experiências nas quais os serviços de saúde transformam-se em espaços de estímulo da sociabilidade entre seus usuários, para a constituição de novos amigos, de trocas de informações e experiências e orientações que vão aos poucos restaurando o tecido social comunicativo com a criação e extensão de atividades para fora do âmbito das práticas de saúde (Luz, 2001, p.134). Nessas experiências desenvolvidas nos sistemas locais de saúde, pode se afirmar que surge uma tendência nos processos de trabalho e nas equipes de 
saúde contra-hegemônica ao individualismo e à fragmentação predominante.

A incorporação de valores de solidariedade e reconhecimento do outro como sujeito autônomo da atenção e do cuidado a saúde, conformam o grande desafio para a utopia da integralidade.

\section{Referências}

CAMARGO, K. R. Jr. Apresentação. In: PINHEIRO, R.; MATTOS, R. A. de (Org.). Os sentidos da integralidade na atenção e no cuidado à saúde. Rio de Janeiro: UERJ/IMS/Abrasco, 2001, p. 11-16.

CAMARGO, K. R. Jr. Um ensaio sobre a (in)definição de integralidade. In: PINHEIRO, R.; MATTOS, R.A. de (Org.). Construção da integralidade: cotidiano, saberes e práticas em saúde. Rio de Janeiro: UERJ/ IMS/ABRASCO, 2003, p. 35-44.

CANGUILHEM, G. O normal e o patológico. Trad. Maria Teresa Redig de Carvalho Barrocas e Luís Octávio Ferreira Barreto Leite. 5. ed. Rio de Janeiro: Forense Universitária, 2002.

CECÍlIO, L. C. As Necessidades de saúde como centro estruturante na luta pela integralidade e eqüidade na atenção em saúde. In: PINHEIRO, R.; MATTOS, R. A. de (Org.). Os sentidos da integralidade na atenção e no cuidado à saúde. Rio de Janeiro: UERJ/ IMS/ABRASCO, 2001. p.113-126.

COSTA, J. S. D. da et al. Auditoria médica: avaliação de alguns procedimentos inseridos no programa de atenção integral à saúde da mulher no posto de saúde de vila municipal, Pelotas, Rio Grande do Sul, Brasil. Cadernos de Saúde Pública, Rio de Janeiro, v.14, n. 1, p. 43-49, jan.-mar., 1998.
FREUD, S. Más allá del principio del placer. Obras Completas II: una teoría sexual y otros ensayos. Buenos Aires; Santiago Rueda, 1952[1920], p. 217-275. 275 p.

GADAMER, H. G. El estado oculto de la salud. Barcelona: Gedisa, 1996. 190 p.

HEIDEGGER, M. Ser e tempo. v. 1. Petrópolis: Vozes, 1989. $263 \mathrm{p}$.

LUZ, M. Políticas de descentralização e cidadania: novas práticas de saúde no Brasil atual. In: PINHEIRO, R.; MATTOS, R. A. de. (Org.). Os sentidos da integralidade na atenção e no cuidado à saúde. Rio de Janeiro: UERJ/IMS/Abrasco, 2001. p.17-38.

MARCUSE, H. Eros e civilização. 8. ed. Rio de Janeiro: Livros Técnicos e Científicos S.A., 1999. 223p.

MATTOS, R. A. de. Os Sentidos da integralidade: algumas reflexões acerca dos valores que merecem ser defendidos. In: PINHEIRO, R; MATTOS, R. A. de (Org.). Os sentidos da integralidade. Rio de Janeiro: IMS/UERJ/ABRASCO, 2001. p. 39-64.

PINHEIRO, R. As práticas do cotidiano na relação oferta e demanda dos serviços de saúde: um campo de estudo e construção de integralidade. In:Pinheiro, R.; MATTOS, R. A. de (Org.). Os sentidos da integralidade na atenção e no cuidado à saúde. Rio de Janeiro: UERJ/IMS/Abrasco, 2001, p. 65-112.

PLATÃo. Fedro. Trad. Alex Marins. São Paulo: Martins Claret, 2003.

SONTAG, S. A doença como metáfora. Trad. Márcio Ramalho. Rio de Janeiro: Graal, 1984. 108p. 